
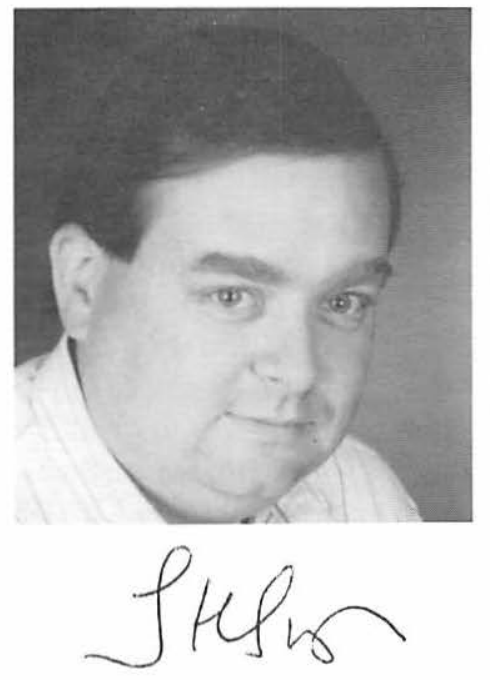

\section{You Can Take The Boy Out of the Language Lab....}

Pete Smith

\section{University of Texas--Arlington}

Nearly two years ago, I accepted a new position at my institution. I have tried to stay in contact with linguistic education and language media, but the demands of the new job have been significant. I must admit that I even had begun to think about my days in the language lab as a "former career."

At about the same time that my professional roles changed, I started to serve as a volunteer with a non-profit organization in Dallas, North Texas Taping and Radio for the Blind - an agency that, among its many services, records and distributes audiotape versions of school textbooks to learners in Texas. By conservative estimates, more than 75,000 schoolchildren in the state will make use of N.T.T.R.B. textbook recordings this year. To my surprise, I found that the skills I had acquired in my "former" career had real meaning, even in this new context.

Over the past 29 years, thousands of North Texas Taping volunteers reading for the visually-impaired and learning-challenged have recorded more than 2200 textbook and literary titles; readings of textbooks often run to 60 or 7090 minute cassettes/title. And just like my "former" media center, N.T.T.R.B. boasts an audio archive of educational materials. Granted, the spoken word holdings of North Texas Taping are a bit larger in scope than the accumulated collection of master tapes which sat on a shelf at U.T.A.'s Language Acquisition Center: the N.T.T.R.B. library holds somewhere between 50,000 and 75,000 hours of recorded audio! Yet this non-profit organization faces exactly the same issues I had encountered in my "former" career. How does one preserve such a priceless archive and utilize it most efficiently, so as to distribute taped materials to the greatest number of learners? How might we celebrate and advertise such a valuable educational language resource? And how to preserve such a rich audio legacy for future generations of learners, with the help of digital technology? 
"It is comforting for me to know that core passions such as a love for learning and an appreciation of the vibrancy that electronic media can bring to education may follow me and follow all of us in careers to come!"
The Executive Director of the agency put my "former" skills to use right away. We have already crafted a plan to digitize significant portions of the massive N.T.T.R.B library, as well as to take the reading efforts of more than 300 volunteers annually and begin digital recording of new items as they are initially read aloud. The "work" is, for me, almost a living connection to an earlier life.

Over the course of a modern-day career, experts tell us that we will change jobs an average of seven times. It is comforting for me to know that core passions such as a love for learning and an appreciation of the vibrancy that electronic media can bring to education may follow me and follow all of us in careers to come!

This double issue of the IALL Journal that you hold in your hands is also the result of a passion for education. Peter Liddell (University of Victoria) serves as Guest Editor for this celebration of language media, with the reprinting of six feature articles first presented at FLEAT/IALL ' 97 and then codified in the Proceedings of that conference. Peter's love of language media scholarship was evident to all of us who visited him in Victoria, and I am proud that the Journal might further reflect his professional passion and the excitement that FLEAT III/IALL' 97 stirred in all of us! 